\title{
A ELABORAÇÃO DE TAREFAS PARA O ENSINO DE LÍNGUA PORTUGUESA A PARTIR DA TEORIA BAKHTINIANA DE GÊNEROS DO DISCURSO
}

\section{THE ELABORATION OF TASKS FOR THE TEACHING OF PORTUGUESE LANGUAGE FROM THE BAKHTINIAN THEORY OF DISCOURSE GENRES}

\section{Maíra da Silva Gomes ${ }^{* 1}$ Letícia Grubert dos Santos ${ }^{* \star}$}

\section{RESUMO}

Ancorado na perspectiva teórica do Círculo de Bakhtin, este artigo propõe uma reflexão sobre critérios de elaboração e de avaliação de tarefas de produção escrita para o ensino de Português como Língua Adicional (PLA). Considerando que a formação do professor passa, em grande medida, pelas suas práticas de elaboração, avaliação e adaptação de tarefas didáticas, de acordo com as necessidades de seu grupo, torna-se premente a discussão e a reflexão sobre os processos envolvidos nessas atribuições do trabalho do professor, sobretudo na área de PLA. Por meio da explicitação das etapas de construção de uma tarefa de produção escrita, e pela apresentação e análise dos parâmetros de avaliação da produção textual, busca-se contribuir para a discussão sobre elaboração de materiais didáticos que tenham como base a perspectiva de gêneros do discurso de Bakhtin, já que a área de PLA no Brasil ainda carece de políticas linguísticas que estabeleçam parâmetros direcionadores para o ensino nos contextos em que o português como língua adicional é usado.

Palavras-chave: gêneros do discurso, tarefas de escrita, PLA.

\section{ABSTRACT}

Anchored in the theoretical perspective of the Bakhtin Circle, this article proposes a reflection on criteria for the elaboration and evaluation of written production tasks for the teaching of Portuguese as an Additional Language (PLA). Considering that teacher training passes, to a large extent, through its practices of elaboration, evaluation and adaptation of didactic tasks, according to the needs of its group, it becomes urgent to discuss and reflect on the processes involved in these assignments of the work of the teacher, especially in the area of PLA. Through the explanation of the stages of construction of a written

\footnotetext{
* Instituto Federal de Educação, Ciência e Tecnologia do Rio Grande do Sul, IFRS, Restinga, Porto Alegre, RS, Brasil. maira.gomes@restinga.ifrs.edu.br

Orcid: https://orcid.org/0000-0003-2810-1607

1. Bolsista CAPES

**Instituto Federal de Educação, Ciência e Tecnologia Sul-rio-grandense, IFSul, Gravataí, Gravataí, RS, Brasil. legrubert@gmail.com Orcid: https://orcid.org/0000-0003-3851-873X
} 
production task, and through the presentation and analysis of the evaluation parameters of textual production, we seek to contribute to the discussion about the elaboration of didactic materials based on the gender perspective of Bakhtin's discourse, since the PLA area in Brazil still lacks linguistic policies that establish guidelines for teaching in the contexts in which Portuguese as an additional language is used.

Keywords: discourse genres, writing tasks, PLA

\section{INTRODUÇÃO}

O ensino de Português como Língua Adicional (PLA) ${ }^{2}$ tem avançado muito nos últimos anos, haja vista o crescente número de inscritos no Exame Celpe-Bras, como apontam os dados disponibilizados pelo Instituto Nacional de Estudos e Pesquisas Educacionais (INEP), que mostram que em 2018, ao completar 20 anos de atuação, o Exame Celpe-Bras contava com mais de sete mil participantes ${ }^{3}$. Some-se a isso, o interesse de instituições no cenário internacional que buscam professores com qualificação específica na área (CARVALHO e SCHLATTER, 2011; SANTOS, $2017^{4}$ ). Percebe-se também que pesquisas relacionadas ao ensino e à avaliação de Português como Língua Adicional (PLA), no Brasil, se desenvolveram muito nos últimos anos, ancoradas, em sua maioria, em uma perspectiva de linguagem com foco no uso, nas interações verbais, se considerarmos os estudos publicados nesse período (SANTOS, 2007; GOMES, 2009; ANDRIGHETTI, 2009; SCHOFFEN 2009; SCARAMUCCI, 2004; KRAEMER, 2012; MOREIRA, 2015, dentre outros). Embora tais avanços tenham sido percebidos no contexto de pesquisa sobre ensino e avaliação, eles não foram observados no contexto institucional para a elaboração de diretrizes para o ensino e para a formação de professores de PLA. Segundo Schoffen e Martins (2016), a área de PLA no Brasil ainda carece de políticas linguísticas que estabeleçam parâmetros direcionadores para o ensino nos diferentes ${ }^{5}$ contextos em que o português como língua adicional é usado. Segundo esses autores, muitos estudos apontam, a esse respeito, que o construto de linguagem subjacente ao Exame Celpe-Bras funciona, em grande medida, como um parâmetro orientador de

2. Utilizamos o termo Português como Língua Adicional (PLA) neste trabalho, pois partimos do pressuposto de que, ao aprendermos uma língua, estamos adicionando uma nova língua ao nosso repertório linguístico, sendo que ela será utilizada pelo falante à medida que se tornar necessária para a sua interação verbal (Schlatter e Garcez, 2009).

3. Disponível em <http://inep.gov.br/web/guest/acoes-internacionais/celpe-bras $>$

4. Apresentação de comunicação individual proferida pela autora no VI EMEP (Encontro Mundial sobre o ensino de Português), na Florida International University, em agosto de 2017.

5. Entendemos contextos aqui como os grupos para os quais o PLA é ensinado: PLA para alunos em imersão, PLA para alunos em não imersão, PLA como língua de acolhimento, PLA como língua de herança, dentre outros. 
práticas de ensino tanto no Brasil, quanto no exterior, uma vez que se trata de um Exame oficial do Estado brasileiro para a certificação de proficiência de estrangeiros em língua portuguesa. Por ser de natureza comunicativa e apresentar um conceito de proficiência como uso adequado da língua para desempenhar ações no mundo (BRASIL, 2006), a concepção de linguagem subjacente ao Exame pode ser vinculada à perspectiva de linguagem do Círculo de Bakhtin (2003). Nesse sentido, de acordo com Scaramucci (2004), o Exame não se restringe apenas ao seu caráter oficial, qual seja, avaliar e certificar seus examinandos, mas também exerce um papel importante nas práticas educacionais de PLA.

No tocante à formação de professores, de acordo com Schoffen e Martins (2016), ainda que haja centros de formação de professores estabelecidos dentro de instituições renomadas, como é o caso do Programa de Português para Estrangeiros da Universidade Federal do Rio Grande do Sul, temos a notícia de que no Brasil há apenas quatro instituições de nível superior que oferecem graduação específica em PLA, a saber, Universidade de Brasília, Universidade Federal da Bahia, Universidade Estadual de Campinas (Unicamp), Universidade Federal da Integração da LatinoAmericana (UNILA), além de uma instituição que oferece especialização em nível de Pós-graduação no estado do Rio de Janeiro (PUC-RIO). Diante disso, percebese a necessidade de mais ações direcionadas para a formação do professor de PLA e para o fortalecimento dessa área.

Ao considerarmos que a formação do professor passa, em grande medida, pelas suas práticas de elaboração e adaptação de tarefas didáticas de acordo com as necessidades de seu grupo, bem como com a tomada de decisão em relação ao desempenho de seus alunos nas atividades didáticas empreendidas em sala de aula, torna-se premente a discussão e a reflexão sobre os processos envolvidos nessas atribuições do trabalho do professor, sobretudo na área de PLA, uma vez que ainda é um campo em desenvolvimento, como discutido acima.

Neste artigo, trazemos a proposta de elaboração de uma tarefa que integra leitura e produção escrita e de parâmetros de avaliação a partir de uma visão sociointeracionista de gênero do discurso (BAKHTIN, 2003 [1979]), de modo a dialogar com o professor de PLA a respeito dos objetivos que temos ao elaborarmos tarefas de uso da linguagem, isto é, propostas de atividades que possibilitam o engajamento do aluno em situações plausíveis de interações comunicativas. Por meio da explicitação das etapas de construção da tarefa, da discussão sobre o contexto discursivo estabelecido pelo enunciado da mesma e pela apresentação dos parâmetros de avaliação da produção escrita, pretendemos propor ao professor de PLA a reflexão sobre a elaboração de materiais didáticos que tenham como base a perspectiva de linguagem bakhtiniana. 
Na primeira seção do trabalho, apresentamos a concepção de linguagem à qual nos afiliamos e discutimos a noção de gênero discursivo com base no Círculo de Bakhtin (2003 [1979]). Posteriormente, apontamos algumas questões norteadoras para a elaboração de tarefas que envolvam as habilidades de leitura e produção escrita de forma integrada para, então, apresentarmos a tarefa de leitura e produção escrita proposta para análise, operacionalizando os conceitos discutidos. Por fim, fazemos uma reflexão sobre os critérios que norteiam a avaliação da produção escrita do aluno nesse tipo de tarefa.

\section{A CONCEPÇÃO DE LINGUAGEM SOB A PERSPECTIVA DO CÍRCULO DE BAKHTIN ${ }^{6}$}

A concepção de linguagem do Círculo de Bakhtin é de natureza social e dialógica, pois todo enunciado é dirigido a alguém que responde ativamente ao que foi dito; não existe, nesse sentido, enunciado monológico.Para o círculo de Bakhtin (BAKHTIN/ VOLOSHINOV, 2006, [1929- 1930], p.123), a real natureza da língua não é um sistema abstrato desvinculado do uso, mas são as enunciações realizadas nas interações verbais entre falantes socialmente organizados.

[...] a verdadeira substância da língua não é constituída por um sistema abstrato de formas linguísticas (língua como sistema de formas - objetivismo abstrato) nem pela enunciação monológica isolada (língua como expressão de uma consciência individual - subjetivismo idealista), nem pelo ato psicofisiológico de sua produção (atividade mental), mas pelo fenômeno social da interação verbal, realizada pela enunciação (enunciado) ou pelas enunciações (enunciados). A interação verbal constitui assim a realidade fundamental da língua.

Bakhtin distancia-se tanto de teorias que focam seus estudos na língua enquanto sistema de regras e formas, quanto de teorias que percebem a língua somente como expressão da consciência individual do falante. Ao contrário disso, a teoria bakhtiniana centra-se no estudo dos enunciados, já que a linguagem é concebida a partir de um ponto de vista histórico e social, em condições e situações específicas de interação verbal: "O emprego da língua efetua-se em forma de enunciados (orais ou escritos) concretos e únicos, proferidos pelos integrantes desse ou daquele campo da atividade humana" (BAKHTIN, 2003 [1979], p.11).

6. As ideias aqui expostas são atribuídas ao Círculo de Bakhtin (grupo de intelectuais russos, dentre os quais fizeram parte Bakhtin, Voloshinov e Medvedev). Há discussão entre os pesquisadores sobre a autoria de alguns textos da década de 1920, publicados por Voloshinov e Medvedev e atribuídos à Bakhtin (Rodrigues, 2006, p. 152). 
Bakhtin dá central importância ao conceito de gêneros do discurso, já que falamos sempre por meio de determinados gêneros em cada campo da comunicação humana. Assim, na perspectiva bakhtiniana, não podemos tratar do uso da linguagem sem considerar o conceito de gêneros do discurso, pois todo enunciado de qualquer extensão, ou tipo, pertence a um gênero.

Falamos apenas através de determinados gêneros do discurso, isto é, todos os nossos enunciados possuem formas relativamente estáveis e típicas de construção do todo. Dispomos de um rico repertório de gêneros de discursos orais (e escritos). Em termos práticos, nós os empregamos de forma segura e habilidosa, mas em termos teóricos podemos desconhecer inteiramente a sua existência. (BAKHTIN, 2003 [1979], p.282)

Salientando o processo de interação verbal, Bakhtin define gêneros como tipos relativamente estáveis de enunciados elaborados em cada esfera da comunicação. Os gêneros não são enfocados como conjuntos de textos que partilham apenas de determinadas características formais. Em vez de pensar em gênero pelo viés do produto (formato e categorização), o pensador russo discute a noção de gênero pelo viés da produção (propósito, interlocutores, suporte, etc.). Os tipos de enunciados são sempre correlacionados as suas funções na interação socioverbal. Para definir gêneros como sendo tipos relativamente estáveis de enunciados, Bakhtin não parte da análise do produto, das características formais dos textos, e sim da relação entre os tipos de enunciados e do que os interlocutores fazem com eles no interior de uma determinada esfera de utilização da linguagem (FARACO, 2003). Assim, se queremos analisar a estabilidade de enunciados, partindo da noção de que a utilização da linguagem e a atividade humana são inter-relacionadas, não podemos delimitar características formais de textos desvinculados do campo de comunicação, dos interlocutores envolvidos e das finalidades relacionadas às condições de produção específicas de tais enunciados.

Afirmando que os tipos são relativamente estáveis, Bakhtin salienta tanto a historicidade dos gêneros, como a imprecisão de suas características e fronteiras (FARACO, 2003). Como os gêneros estão diretamente relacionados às esferas de atividade humana, eles não são permanentes, e sim flexíveis: transformam-se à medida que aspectos da atividade humana mudam; outros gêneros surgem à medida que novas atividades humanas passam a acontecer. Pode-se dizer, então, que a noção de gênero proposta por Bakhtin engloba

[...] a situação de produção de um dado discurso (quem fala, para quem, os lugares sociais dos interlocutores, posicionamentos ideológicos, em que situação, em que momento histórico, em que veículo, com que objetivo, finalidade ou intenção, em que registro, etc.), o conteúdo temático - o que pode ser dizível em um dado gênero, a construção composicional - sua forma de dizer, sua organização geral que não é inventada a cada vez que nos comunicamos, mas que 
está disponível em circulação social - e seu estilo verbal - seleção de recursos disponibilizados pela língua, orientada pela posição enunciativa do produtor do texto (BARBOSA, 2000, p. 153).

Interpretar a concepção de gênero de discurso apenas como a de tipos de textos que compartilham de determinadas características formais pode contribuir para a recorrência das mesmas práticas pedagógicas tradicionais de ensino de língua, que privilegia regras gramaticais descontextualizadas das situações de uso da linguagem. Dizer que e-mail é um gênero que deve ter uma abertura e um fechamento, uma linguagem informal, etc., é focar no produto e não no processo de produção, pois há vários e-mails com características formais diferenciadas, dependendo da situação de interlocução estabelecida na comunicação. Um e-mail para um diretor de uma empresa para solicitar uma vaga de emprego possuirá um projeto enunciativo e características bem diferentes de um e-mail para um amigo com o objetivo de contar sobre o fim de semana.

O outro, o interlocutor, exerce importância central no construto de linguagem do Círculo, pois todo o enunciado é constituído pelo outro: "Cada gênero do discurso, em cada campo da comunicação discursiva, tem sua concepção típica de destinatário que o determina como gênero" (BAKHTIN, 2003 [1979], p.63). Ao interagirmos verbalmente, construímos nossos enunciados a partir de uma série de restrições impostas pela situação comunicativa e pelo gênero discursivo, mas principalmente pelo interlocutor. $\mathrm{O}$ falante, para enunciar, leva em conta uma série de fatores sobre seu interlocutor que serão constitutivos de seu enunciado: o lugar social que o interlocutor ocupa (hierarquia), a opinião que o interlocutor provavelmente tenha do assunto a ser tratado, a relação de proximidade entre eles, etc. Todos esses fatores orientam e delimitam as maneiras de dizer. As escolhas lexicais e estruturais não são feitas de forma aleatória pelo enunciador, mas são fortemente determinadas pela interlocução estabelecida em cada interação verbal. Conforme Bakhtin (2003 [1979], p. 63 e 64),

Ao construir o meu enunciado, procuro defini-lo de maneira ativa; por outro lado, procuro antecipá-lo, e essa resposta antecipável exerce, por sua vez, uma ativa influência sobre o meu enunciado (dou resposta pronta às objeções que prevejo, apelo para toda a sorte de subterfúgios, etc). Ao falar, sempre levo em conta o campo aperceptivo da percepção do meu discurso pelo destinatário: até que ponto ele está a par da situação, dispõe de conhecimentos especiais de um dado campo cultural da comunicação; levo em conta as suas concepções e convicções, os seus preconceitos, as suas simpatias e antipatias. Essa consideração irá determinar também a escolha do gênero do enunciado e a escolha dos procedimentos composicionais e, por último, dos meios linguísticos, isto é, o estilo do enunciado.

Nessa visão, não existe compreensão passiva, mas, sim, uma compreensão ativamente responsiva. $\mathrm{O}$ ouvinte não tem uma posição menos importante do que 
o falante na interação verbal. Ao contrário, ele, ao responder ativamente, assume a posição de falante: "Toda compreensão da fala viva, do enunciado vivo é de natureza ativamente responsiva; toda compreensão é prenhe de resposta, e nessa ou naquela forma a gera obrigatoriamente: o ouvinte se torna falante" (BAKHTIN, 2003 [1979], p. 269)

O interlocutor é tão importante na teoria que, conforme Bakhtin, o falante está determinado pela atitude responsiva do ouvinte quando enuncia. $\mathrm{O}$ falante constrói seu modo de dizer dependendo da situação em que se encontra com o ouvinte e reelabora seu dizer, dependendo da atitude responsiva do ouvinte. Quanto a isso, Bakhtin (2003 [1979], p. 26) afirma que

O próprio falante está determinado precisamente a essa compreensão ativamente responsiva: ele não espera uma compreensão passiva, por assim dizer, que apenas duble seu pensamento em voz alheia, mas uma resposta, uma concordância, uma participação, uma objeção, uma execução, etc. (os diferentes gêneros discursivos pressupõem diferentes diretrizes de objetivos, projetos de discurso dos falantes ou escreventes).

Todo enunciado é pleno de tonalidades dialógicas, tanto por ser sempre direcionado a um interlocutor, quanto por ser relacionado com outros enunciados e outros discursos: "Cada enunciado é um elo na corrente complexamente organizada de outros enunciados" (BAKHTIN, 2003 [1979], p.26). Portanto, "nessa perspectiva, toda enunciação, por mais monológica que possa parecer, é, em sua essência, dialógica, pois é impregnada por valorações de outros discursos e sujeitos, como a de um ouvinte em potencial" (DI FANTI, 2015, p. 422)

Desse modo, se queremos possibilitar que os alunos usem a língua portuguesa a partir da perspectiva de gêneros do discurso de Bakhtin, devemos construir tarefas que apresentem situações comunicativas claras, interlocutores específicos e propósitos a serem cumpridos para que os alunos selecionem as maneiras de dizer mais adequadas às restrições impostas pelo gênero apresentado na tarefa.

Apresentamos, na seção seguinte, algumas questões norteadoras para a elaboração de tarefas integradas de leitura e produção textual com base na concepção de linguagem bakhtiniana.

\section{ELABORANDO TAREFAS A PARTIR DA PERSPECTIVA BAKHTINIANA DE GÊNERO DO DISCURSO}

Entendemos que tanto a leitura quanto a escrita envolvem múltiplas habilidades e conhecimentos prévios que auxiliam leitor/escritor a reagir ao texto de diversas formas. De acordo com Schlatter (2009, p. 13), ler é "(re)agir de acordo 
com a expectativa criada pelo gênero discursivo". Nesse sentido, a leitura não é um processo passivo, em que o leitor apenas busca/recebe informações do texto, pelo contrário, o ato de ler sempre envolve uma atitude ativamente responsiva. Concordamos com o texto ou discordamos dele, mobilizamos outras informações para completar o que não foi dito, ou seja, sempre assumimos uma posição ativa em relação a outros enunciados, estabelecendo relações dialógicas com outros discursos.

No que tange à produção escrita, também se pode afirmar que escrever é produzir enunciados em um gênero do discurso, em que tanto a construção composicional, quanto o estilo e o conteúdo temático são determinados pelas restrições impostas na situação comunicativa, como o campo de utilização da língua (jurídica, jornalística, pedagógica, etc.), propósito enunciativo, o enunciador, (os) interlocutor (es) e o suporte/ meio de circulação do texto. Conforme Bakhtin (2003 [1979], p.11 e 12),

O emprego da língua efetua-se em forma de enunciados (orais e escritos), concretos e únicos, proferidos pelos integrantes desse ou daquele campo da atividade humana. Esses enunciados refletem as condições específicas e as finalidades de cada referido campo não só por seu conteúdo (temático) e pelo estilo da linguagem, ou seja, pela seleção dos recursos lexicais, fraseológicos e gramaticais da língua, mas, acima de tudo, por sua construção composicional.

Leitura e escrita são consideradas, neste artigo, como ações inter-relacionadas de uso da linguagem, já que ao lermos, produzimos sentido, e ao escrevermos, mobilizamos as leituras feitas anteriormente: "a inter-relação é entendida como uma construção de sentidos, resultante de um processo interativo entre leitura e escrita" (ROTTAVA, 2001, p. 29).

Para refletir essa concepção de leitura e escrita na elaboração de tarefas integradas para o ensino de língua adicional, entendemos que o professor desempenha um papel fundamental como elaborador de material didático e como mediador de um trabalho voltado para o uso da linguagem em sala de aula. Não basta que o professor leve textos autênticos para a sala de aula, no intuito de aproximar-se de uma visão comunicativa de ensino, se o texto é utilizado apenas como pretexto para ilustrar/explorar algum ponto gramatical. Concordamos com Rodrigues (2006, p. 32) quando afirma que "um bom professor é aquele capaz de teorizar sobre sua própria prática, aquele que sabe explicar por que ensina da maneira como ensina e por que obtém certos resultados e não outros". Partindo dessas premissas, listamos, a seguir, alguns passos que podem auxiliar o professor a elaborar tarefas integradas de leitura e produção escrita que espelhem a concepção de linguagem do Círculo 
de Bakhtin, e apresentamos um exemplo de tarefa que integra leitura e produção escrita para alunos de nível intermediário ${ }^{7}$ de português como língua adicional.

\section{Passo 1: Pensar na temática e no gênero discursivo como elementos de motivação para as práticas de leitura e produção escrita em PLA}

O passo 1 está vinculado aos objetivos do curso/ programa de ensino, bem como ao nível de proficiência dos alunos. O termo 'motivação' é entendido aqui como sendo um tópico de aprendizagem de interesse e/ou necessidade do aluno. Se pretendemos elaborar uma tarefa de leitura e produção escrita para um aluno de nível básico em contexto de imersão, por exemplo, em primeiro lugar, teremos de pensar nas temáticas que são relevantes para esse perfil de aluno, e, a partir disso, selecionar os gêneros que poderiam ser utilizados para o trabalho com tais temáticas. Uma possibilidade, por exemplo, seria o trabalho com a temática alimentação e, então, a escolha do gênero 'cardápio', já que este é um dos gêneros que provavelmente fará parte da rotina dos alunos, enquanto usuário de PLA, uma vez que, em pouco tempo, ele deverá identificar certos tipos de comidas, avaliar o preço das refeições, fazer pedidos ao garçom, dentre outras ações, para poder atuar de forma autônoma nas situações relacionadas a esse tema. Sendo assim, poderíamos considerar o trabalho com o gênero 'cardápio' relevante e motivador para esse público-alvo. $\mathrm{O}$ aluno deve ter um propósito relevante de leitura do texto base, para que as informações desse texto sejam úteis para sua produção final, ou seja, para a escrita do gênero almejado.

Nesse sentido, à medida que as tarefas didáticas realizadas em sala de aula assemelham-se aos propósitos de leitura e escrita que são possíveis no contexto de atuação sociodiscursivo do aluno enquanto usuário de PLA, promove-se a oportunidade de práticas discursivas relacionadas às necessidades de uso da linguagem dos alunos (perfil dos alunos, nível de proficiência, dentre outros). Portanto, nesta acepção, é importante ter em conta que não podemos utilizar um texto como base de leitura apenas porque queremos que o aluno produza determinado gênero, se este não for relevante para ele, conforme seus interesses e necessidades de interação na língua adicional.

7. Em relação ao nível intermediário estabelecido para a tarefa deste trabalho, nos valemos dos descritores de nível do Programa de Português como Língua Estrangeira da UFRGS (PPE). Para mais informações sobre a questão de nivelamento dos alunos e do currículo dos cursos nesse programa de extensão de ensino, ver Santos (2007) e Kraemer (2012). 
Passo 2: A escolha do texto autêntico e sua implicação para a elaboração de tarefas didáticas

Para tornar possível uma aproximação entre as tarefas de leitura e produção escrita elaboradas com fins didáticos e as esferas da comunicação nas quais o falante de PLA possivelmente estará inserido, com base no construto bakhtiniano, julgamos ser imprescindível o trabalho com textos autênticos em sala de aula. Segundo Little e Singleton (1988), materiais "autênticos" são materiais desenvolvidos para preencher um propósito social na comunidade linguística em que foram produzidos. Em outras palavras, consideramos textos autênticos aqueles que não foram produzidos com fins didáticos, preservando, assim o seu layout original, fonte de publicação, contexto sócio-histórico em que foi produzido, dentre outros. Sob essa perspectiva, a elaboração de tarefas didáticas a partir de textos autênticos permite a exploração de suas condições de produção e de suas esferas de atuação. Além disso, as questões culturais que vêm impressas em textos autênticos possibilitam a discussão em sala de aula acerca de outros elementos da linguagem (variedades linguísticas, contexto sociocultural de atuação do texto, dentre outras), revelando "o trabalho de língua e cultura como algo indissociável" (BRASIL, 2006). Como veremos adiante, o texto que serve como base para a elaboração da tarefa de leitura e produção escrita discutida neste artigo faz parte do universo de textos que circulam na internet e são lidos por muitos usuários do português brasileiro.

Passo 3: A elaboração do enunciado da tarefa integrada de leitura e produção escrita

É no momento da elaboração do enunciado de uma tarefa integrada de leitura e produção escrita que o professor deverá delimitar a situação de interação verbal e o gênero discursivo necessário para a escrita do aluno. A partir disso, é necessário explicitar as restrições mobilizadas pelo gênero discursivo: enunciador (quem escreve o texto), interlocutor (para quem o texto se dirige), o propósito enunciativo (a finalidade do texto), o suporte (o local de publicação e/ou de circulação do texto). Esses elementos são constitutivos do uso da linguagem em situações autênticas de comunicação e, portanto, se queremos elaborar tarefas de produção escrita que se aproximam de situações de interação verbal extra-classe, devemos explicitá-los na elaboração do enunciado. Além disso, a seleção de informações e recursos linguísticos feitos pelo aluno para a escrita de seu texto é determinada pela interlocução projetada pelo enunciado da tarefa. 
No caso da tarefa proposta neste trabalho, como veremos em seguida, delimitamos os propósitos da tarefa de leitura e produção escrita com base em uma situação de uso da linguagem que poderia ser relevante para usuários de português como língua adicional: ler um texto de blog de viagem a respeito de uma cidade turística brasileira, tendo por finalidade conhecer as atividades do local. Além disso, pensamos na possibilidade de escrita de um e-mail em resposta a um amigo que também teria interesse pelo local.

Passo 4: Como trabalhar os recursos linguísticos nesse tipo de tarefa

Numa perspectiva de uso da linguagem, baseada em gêneros discursivos, os recursos linguísticos devem ser trabalhados à medida que se tornam relevantes para a compreensão e produção escrita do aluno. De acordo com Schlatter e Garcez (2009, p.147), "para cada unidade de ensino, selecionamos os recursos linguísticos considerados relevantes para a situação de comunicação proposta e focalizamos neles o trabalho e a prática de sala de aula".

Portanto, o professor deverá levar em conta o perfil de sua turma (nível de proficiência, conhecimento prévio, entre outros) e as características do gênero discutido na tarefa para, então, selecionar os recursos linguísticos que deverão ser o foco do trabalho em sala de aula. Em relação à produção escrita, é a situação de interlocução proposta pela tarefa que orientará a mobilização de determinados recursos linguísticos pelo aluno. Nesse sentido, o aluno deverá utilizar estruturas gramaticais e lexicais de acordo com as restrições enunciativas do gênero discursivo a ser escrito, levando-se em conta a configuração da interlocução projetada no gênero estabelecido pelo enunciado da tarefa (enunciador, interlocutor, propósito, suporte/meio de circulação, dentre outros). Ao problematizar tais elementos no momento de preparação do aluno para a produção escrita, é necessário que o professor promova uma reflexão sobre os recursos linguísticos que podem fazer parte daquela situação de interlocução, dando exemplos de estruturas da língua que estariam adequadas no contexto de produção delimitado pela tarefa.

Passo 5: A avaliação da produção escrita do aluno a partir de uma perspectiva de gêneros discursivos

Como nossa proposta de trabalho com tarefas integradas de leitura e produção textual parte de uma visão de uso da linguagem, entendendo que são os gêneros do discurso os organizadores das práticas de interação verbal, para avaliar produção textual sob essa perspectiva de linguagem, torna-se necessário o 
estabelecimento de critérios de avaliação que permitam fazer inferências acerca da adequação discursiva do aluno em relação ao gênero solicitado pela tarefa. Em relação a isso, Gomes (2009, p. 8) lembra que

\begin{abstract}
Se usamos a linguagem por meio de gêneros do discurso, ao avaliar o uso da linguagem estamos, necessariamente, avaliando esses gêneros, de modo que as propostas de produção de texto que visam ao ensino e aprendizagem de uma língua adicional devem apresentar pistas sobre os contextos de uso que estarão orientando a leitura e a produção escrita dos textos solicitados.
\end{abstract}

Portanto, o enunciado da tarefa de leitura e produção escrita deverá tornar explícitas as restrições do gênero esperado e, consequentemente, os aspectos que serão levados em conta para a avaliação do texto do aluno (GOMES, 2009). É importante salientar que não basta que elaboremos tarefas integradas de leitura e produção textual que privilegiem a noção sócio-discursiva de gêneros discursivos, se utilizarmos critérios de avaliação que focalizem apenas a correção de itens linguísticos, pois é pela avaliação que explicitamos para o aluno o que valorizamos, enquanto objeto de aprendizagem, e o que ainda pode ser melhorado. No caso da tarefa proposta neste trabalho, de nada vale que o aluno produza um texto com poucas inadequações linguísticas, se não demonstrar compreensão do propósito da tarefa e não produzir um texto dentro do gênero esperado. Para avaliar a adequação do texto do aluno ao propósito comunicativo delimitado pela tarefa, portanto, são necessários parâmetros de avaliação condizentes com a visão de linguagem utilizada para a elaboração do enunciado da tarefa de leitura e produção escrita.

Pensando nos critérios anteriormente arrolados, elaboramos uma tarefa de leitura e produção escrita para alunos de nível intermediário de PLA, em contexto de imersão, no intuito de explicitarmos como o conceito de gênero discursivo do círculo de Bakhtin está atrelado a este tipo de atividade, tanto na proposta de tarefa de ensino, quanto nos parâmetros de avaliação dos textos dos alunos, e de fornecer mais subsídios ao professor de língua adicional.

\title{
3. ELABORANDO UMA TAREFA INTEGRADA DE LEITURA E PRODUÇÃO TEXTUAL PARA NÍVEL INTERMEDIÁRIO
}

A partir do que foi discutido anteriormente sobre os passos para a elaboração de uma tarefa integrada de leitura e produção escrita para o ensino de PLA, descrevemos, a seguir, a tarefa proposta para análise neste artigo. 


\section{Eixo temático da tarefa: Viagem}

Escolhemos a temática 'viagem' (passo 1) para a elaboração da tarefa proposta neste artigo, pois, frequentemente, o assunto é de interesse dos alunos. Ler textos relacionados a cidades turísticas no Brasil e saber interpretar informações sobre festividades, atividades, aspectos culturais, bem como poder contar como foi uma viagem para amigos e "familiares" falantes de português parece ser relevante para os alunos usuários de PLA. O gênero escolhido para a leitura dos alunos, a partir da delimitação da temática, foi o gênero 'texto de blog de viagem'. Sabemos que esse gênero é de ampla circulação em diferentes mídias, o que também poderia ser um elemento motivador para o aluno em termos de propósito de leitura.

No tocante ao passo 2 (escolha do texto autêntico para a leitura e produção textual), selecionamos o texto "Recife-boa viagem" (ver anexo 1), do blog Viaje na viagem (https://www.viajenaviagem.com/destino/recife), que trata de informações turísticas e culturais sobre a cidade do Recife (Pernambuco). O texto ${ }^{8}$ apresenta as principais atividades que o turista pode fazer na cidade, além de possibilitar ao leitor ter uma ideia sobre os melhores períodos para visitar o local. A partir da escolha do texto, há a necessidade de se pensar no encaminhamento da tarefa de leitura e produção escrita. No caso da tarefa proposta neste trabalho, delimitamos o propósito de leitura e produção escrita com base em uma situação de uso da linguagem que poderia ser relevante para os alunos de PLA: compreender as informações a respeito de uma cidade turística brasileira, relatar suas experiências no local e dar dicas sobre o que fazer na cidade para um amigo falante de português. Nesse tipo de proposta de leitura e produção textual, o aluno não poderá simplesmente copiar determinadas informações do texto-base para produzir seu texto, já que ele precisará contar ao amigo o que fez na cidade e, portanto, entender que tipo de atividade a cidade oferece e qual/quais lhe chamam mais atenção, justificando sua escolha. Para que o aluno seja levado a produzir um texto nesse tipo de situação discursiva, é imprescindível que o enunciado da tarefa esteja claro e delimite o propósito enunciativo do texto a ser escrito.

Como veremos a seguir, relacionado ao passo 3 (elaboração do enunciado da tarefa de leitura e produção textual), a proposta de enunciado da tarefa torna explícitos os elementos relacionados à configuração do gênero (o propósito, o papel enunciativo que deverá ser assumido pelo aluno, o(s) interlocutor(es) para o(s) qual(is) o texto será dirigido, o suporte em que o texto circulará, dentre

8. O texto encontra-se no seguinte link: https://www.viajenaviagem.com/destino/recife. Acessado em $10 / 11 / 2018$. 
outros). $\mathrm{O}$ enunciado, por configurar um gênero, acaba, também, delimitando uma série de escolhas enunciativas, como as informações a serem mobilizadas, o nível de formalidade do texto, os recursos linguísticos a serem utilizados, etc. São esses elementos (propósitos, interlocutores, suporte, etc) que direcionam a leitura e a produção escrita do aluno.

Como já discutido anteriormente, promover o trabalho com tarefas que integram leitura e produção escrita em sala de aula possibilita que o aluno interaja em situações de uso da linguagem, uma vez que, ao lermos e ao escrevermos textos, temos uma atitude ativamente responsiva, que, em muitas situações de nossa vida cotidiana, ocorrem de maneira integrada. A exemplo disso, poderíamos pensar que, ao lermos um artigo de opinião sobre as mudanças no currículo escolar brasileiro, poderemos utilizar essa leitura para a escrita de outro gênero discursivo como, por exemplo, a escrita de uma carta do leitor sobre o tema 'educação brasileira' para a revista em que o artigo de opinião sobre o currículo brasileiro de ensino foi vinculado. Dessa forma, as práticas de leitura e produção escrita são constitutivas uma das outras e também podem ser trabalhadas de maneira conjunta na sala de aula de língua adicional. No entanto, destacamos que, embora nossa proposta seja promover um trabalho que integre essas habilidades para um empreendimento pedagógico de ensino, julgamos ser necessário, primeiramente, propor ao aluno questões que focalizam a leitura do texto e a familiarização do aluno com o gênero e a temática de leitura.

No caso de nossa proposta, é necessário, na primeira etapa da tarefa, verificar se o aluno já tem experiência como leitor de blog de viagem e também se traz conhecimentos prévios em relação à cidade do Recife.

\section{Tarefa integrada de leitura e produção escrita}

Leia a tarefa de leitura e produção escrita abaixo e converse com o professor e seus colegas sobre a situação de comunicação proposta.

Enunciado da tarefa de produção escrita:

Imagine que você está em Recife passando as férias e que recebeu o e-mail abaixo de um amigo brasileiro. Responda ao e-mail, utilizando as informações do texto que você leu, Recife Boa Viagem, no link https://www.viajenaviagem.com/destino/recife 


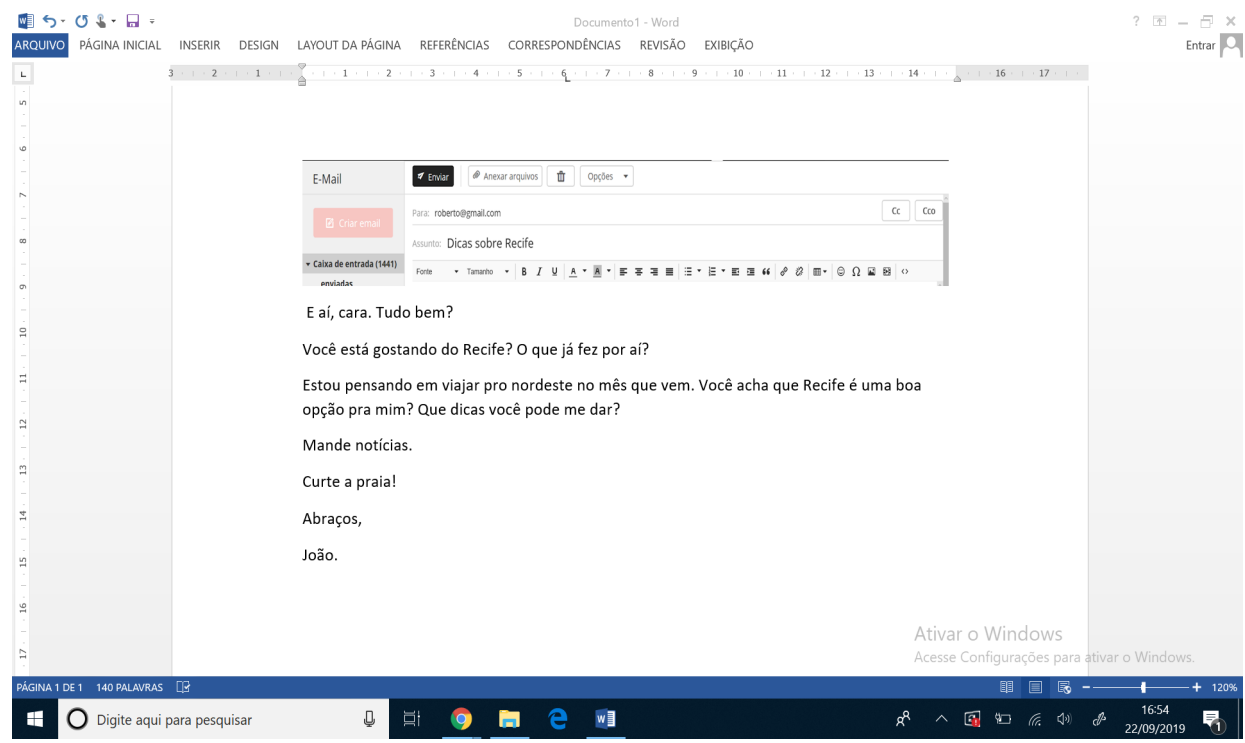

De acordo com o enunciado da tarefa de leitura e produção escrita, o aluno deve assumir o papel de amigo (quem fala), responder as perguntas do e-mail do amigo (para quem fala), com o objetivo de contar o que ele fez no Recife e de auxiliar o interlocutor, dando dicas sobre o que fazer na cidade (propósito do texto). São esses elementos que estabelecerão as maneiras de dizer mais adequadas à situação comunicativa. Em outras palavras, o aluno deverá levar em conta o seu papel enunciativo (quem é ele na situação de comunicação), quem é o seu interlocutor (para quem ele está escrevendo), qual é o propósito de seu texto (os objetivos e as ações que deverá realizar para cumprir os objetivos do texto), o suporte e ou meio de circulação do texto, os recursos linguísticos necessários para tal, dentre outros elementos necessários à configuração da interlocução projetada no gênero discursivo proposto pela tarefa.

\section{AVALIAÇÃO DA PRODUÇÃO ESCRITA DO ALUNO}

A partir da concepção de linguagem bakhtiniana, para a avaliação da produção escrita do aluno, o professor deve privilegiar os aspectos enunciativos da interação verbal firmada pelo texto do aluno, tentando projetar-se como se fosse um interlocutor específico da situação de comunicação estabelecida pelo enunciado da tarefa e, dessa forma, estabelecer os parâmetros de adequação ou inadequação da escrita do aluno. Como forma de organizar os aspectos a serem avaliados pelo 
professor, propomos, a seguir, uma grade de avaliação com critérios estabelecidos a partir do enunciado da tarefa.

\begin{tabular}{|l|l|l|l|l|}
\hline Critérios de avaliação & $\begin{array}{l}\text { Cumpre a } \\
\text { tarefa }\end{array}$ & $\begin{array}{l}\text { Cumpre } \\
\text { Parcialmente }\end{array}$ & $\begin{array}{l}\text { Não cumpre } \\
\text { a tarefa }\end{array}$ & $\begin{array}{l}\text { Sugestão do } \\
\text { professor }\end{array}$ \\
\hline $\begin{array}{l}\text { Enunciador: } \\
\text { É possível identificar o } \\
\text { enunciador projetado pela tarefa } \\
\text { (amigo que está no Recife)? }\end{array}$ & & & & \\
\hline $\begin{array}{l}\text { Interlocutor: } \\
\text { É possível identificar o } \\
\text { interlocutor projetado pela } \\
\text { tarefa (amigo que pede ajuda } \\
\text { sobre os lugares para visitar em } \\
\text { Recife)? }\end{array}$ & & & & \\
\hline $\begin{array}{l}\text { Propósito: } \\
\text { O texto atende ao propósito } \\
\text { solicitado (há indicações sobre } \\
\text { lugares que podem ser visitados } \\
\text { na cidade de acordo com o } \\
\text { perfil do amigo que solicitou as } \\
\text { dicas)? }\end{array}$ & & & & \\
\hline $\begin{array}{l}\text { Recursos linguísticos: } \\
\text { Os recursos linguísticos mobili- } \\
\text { zados estão adequados à situa- } \\
\text { ção de interlocução projetada? }\end{array}$ & & & & \\
\hline
\end{tabular}

Conforme estabelecido na grade de avaliação anterior, o autor do texto (aluno) deve assumir o papel enunciativo de alguém que está no Recife e que tenha recebido um e-mail de um amigo (interlocutor) que lhe pergunta como está sendo a viagem e lhe pede auxílio com informações sobre o local. De modo a cumprir o propósito do texto, é necessário que o aluno se posicione como um amigo que está no Recife e que, portanto, tem informações importantes sobre a cidade para dar ao amigo.

Para cumprir o propósito de forma adequada, o aluno deverá realizar as ações solicitadas (contar ao amigo como está sendo a viagem e narrar as atividades que já fez em Recife, além de dar dicas sobre atividades que o amigo poderia fazer lá). Para isso, com relação às informações selecionadas do texto-base (texto do blog), não há um número exato de informações que o aluno deverá utilizar em seu texto: o importante é que utilize as informações de forma autoral, isto é, retextualize as 
informações do texto base, relacionando-as à sua experiência de turista na cidade, justificando, explícita ou implicitamente, a escolha de determinadas atividades em detrimento de outras, como dicas de viagem para seu amigo. Desse modo, nesse tipo de produção escrita, seria inadequado que o aluno simplesmente copiasse trechos do texto-base com informações de atividades da cidade.

No que tange aos recursos linguísticos, o professor deverá avaliar em que medida as inadequações gramaticais e lexicais presentes na produção escrita do aluno interferem no estabelecimento da interlocução solicitada pela tarefa. Em outras palavras, deve-se verificar o quanto as inadequações de língua prejudicam ou não o entendimento do texto pelo seu leitor (amigo que está enviando o e-mail). Também é importante destacar que, dada a proximidade da relação que normalmente se estabelece nesse contexto de interlocução (relação entre amigos), é possível que a linguagem utilizada no texto seja de tom mais informal e que algumas informações contextuais sejam omitidas.

Caso o aluno cumpra parcialmente a tarefa ou não a cumpra, o professor poderá se valer do eixo de recomendações estabelecido na grade de avaliação para indicar ao aluno, de forma pontual, as questões que prejudicaram o cumprimento da tarefa com sucesso. Nesse caso, pode ser necessário que o professor solicite ao aluno a reescrita do texto.

Como forma de tornar explícito aos alunos a importância da relação de interlocução estabelecida nos textos, uma possibilidade para a dinâmica de leitura dos textos produzidos pelos alunos em sala de aula é propor a eles que troquem os seus textos com os de seus colegas e se coloquem na posição de interlocutor daquela situação de comunicação, isto é, leiam os textos escritos pelos colegas, imaginando que seriam o amigo que recebeu o e-mail. Assim, eles podem avaliar em que medida é possível compreender ou não o texto do colega, bem como refletir sobre a sua própria produção escrita.

\section{CONSIDERAÇÕES FINAIS}

As tarefas integradas partem dos pressupostos de que na leitura as pessoas constroem sentidos, interagem com o texto e com os discursos ali materializados; a escrita também requer a ação de ler, pois todo texto é uma resposta a um texto anterior e se constitui de leituras prévias, é um elo dialógico com outros enunciados precedentes e com discursos instituídos. A noção de gênero como processo, vinculada às atividades sociais e às interações sócio-verbais, deve ser entendida quando pensamos em ensino priorizando o uso da língua. Para focalizar o processo 
da produção de gêneros, devemos propor tarefas que reflitam as concepções teóricas assumidas, de forma a promover o uso da linguagem em sala de aula.

$\mathrm{O}$ uso de material autêntico também é de extrema importância para que as tarefas propostas nesses moldes façam mais sentido. Ao trabalharmos com textos autênticos, que circulam em nossa sociedade, em sala de aula, podemos explorar aspectos extralinguísticos, como a fonte (onde se produzem os textos) dos textos e sua influência na linguagem utilizada, o público alvo, os efeitos de sentido estabelecidos pela organização textual, etc. Para que a tarefa reflita, então, a concepção de gênero trazida pelo Círculo de Bakhtin, é necessário que alguns elementos estejam presentes no enunciado da tarefa, a fim de que se estabeleça um gênero-contrato na situação de comunicação específica. A tarefa deve delimitar o propósito de leitura e de produção escrita para que o aluno tenha um objetivo ao ler e ao escrever. Além disso, é a partir das instruções da tarefa que o aluno deverá adequar a sua linguagem, de acordo com seu interlocutor. Portanto, a partir dessa perspectiva de linguagem, o aluno precisa trabalhar com projeções de papéis enunciativos, assumindo diferentes perspectivas como autor/ produtor de texto, e mobilizar diferentes conhecimentos para dar conta de seu propósito comunicativo.

Uma vez que os enunciados estão intimamente ligados às esferas da atividade humana, a questão da interlocução é crucial quando se adota a perspectiva bakhtiniana: quando dizemos algo, estamos nos dirigindo a alguém em certo contexto. Sendo a linguagem uma realidade social, na qual há espaço para o individual, "o sujeito tem a possibilidade de singularizar-se e de singularizar seu discurso na interação viva com as vozes sociais" (FARACO, 2003, p. 87).

E como a todo processo de ensino subjaz um processo de avaliação, a elaboração de parâmetros de avaliação é também inerente ao trabalho do professor de língua adicional. A avaliação da produção escrita do aluno dependerá das restrições impostas pelo enunciado da tarefa. A especificidade do gênero que será usado, como o contexto, os interlocutores e o propósito restringem tanto as possibilidades da escrita como os critérios de avaliação. Se o enunciado não especifica claramente os papéis que os participantes devem assumir, o professor/avaliador não saberá qual critério deverá usar no momento de verificar se o texto produzido se adequa ou não às especificidades do enunciado da tarefa (GOMES, 2009).

O professor de língua adicional tem, então, papel fundamental na elaboração e avaliação de tarefas didáticas, se considerarmos que, a partir de tarefas de uso da linguagem, podemos promover um trabalho em sala de aula que esteja pautado na leitura e produção de gêneros discursivos (orais ou escritos) e na participação dos alunos em diversas esferas sociais da comunicação. 


\section{REFERÊNCIAS}

ANDRIGHETTI. G. (2009). A elaboração de tarefas de compreensão oral para o ensino de português como língua adicional em níveis iniciais. Dissertação de Mestrado. PPG em Letras, Universidade Federal do Rio Grande do Sul, Porto Alegre.

BAKHTIN, M. (19.79) Estética da criação verbal. São Paulo: Martins Fontes, 2003

BAKHTIN, M. (VOLOSHINOV, V.). (1929-1930). Marxismo e filosofia da linguagem. São Paulo: Hucitec, 2006.

BARBOSA, J. P. (2000). Do professor suposto pelos PCNs ao professor real de língua Portuguesa: são os PCNs praticáveis? In: ROJO, Roxane (Org.). A prática de linguagem em sala de aula: praticando os PCNs. Campinas: Mercado das letras, pp. 149-182.

BRASIL. (2006) Manual do Candidato ao exame Celpe-Bras. Brasília, Secretaria de Educação Superior (SESu), MEC. Disponível em http://portal.mec.gov.br/sesu/arquivos/pdf/ CelpeBras/manualcandidato2006.pdf. Acesso em: 12 dez. 2008.

CARVALHO, S., SCHLATTER, M. (2011). Ações de difusão internacional da língua portuguesa. Cadernos do IL, Porto Alegre, n.42, pp. 260-284.

DI FANTI, M. G. C. (2015). Discurso, mídia e produção de sentidos: questões de leitura e de formação na contemporaneidade. Revista do Programa de Pós-Graduação em Letras da Universidade de Passo Fundo, v. 11, no 2, pp. 418-438.

FARACO, C. A. (2003). Linguagem e Diálogo: As ideias linguísticas do círculo de Bakbtin. Curitiba: Criar Edições.

GOMES. M. (2009). A complexidade de tarefas de leitura e produção escrita no Exame Celpe-Bras. Dissertação de Mestrado. PPG em Letras, Universidade Federal do Rio Grande do Sul, Porto Alegre.

KRAEMER. F. F. (2012). Português língua adicional: progressão curricular com base em gêneros do discurso. Porto Alegre. Dissertação de Mestrado em Letras. Instituto de Letras, Universidade Federal do Rio Grande do Sul, Porto Alegre.

LITTLE, D; SINGLETON, D. (1988). Authentic materials and the role of fixed support in language teaching: towards a manual for language learners. CLCS Occasional Paper 20. Dublin: Centre for Language and Communication Studies. Trinity College. 
MOREIRA, R. S. (2015). Português como língua adicional e letramento crítico: análises das experiências com alunos estrangeiros. International Congress of Critical Applied Linguistics. Brasília.

RODRIGUES, M. S. (2006). O exame Celpe-Bras: reflexões teórico-didáticas para o professor de português para falantes de outras línguas. Dissertação de Mestrado. Programa de Pós-Graduação em Linguística Aplicada, Instituto de Estudos da Linguagem. Unicamp, Campinas.

ROTTAVA, L. (2001). Leitura e escrita como processos interrelacionados de construção de sentidos em contexto de ensino e aprendizagem de português como L2 para bispano-falantes. Tese de Doutorado. Programa de Pós-Graduação em Linguística Aplicada, Instituto de Estudos da Linguagem, Unicamp, Campinas.

SANTOS. L.G. (2007). Avaliação de desempenbo para nivelamento de alunos de português como língua estrangeira. Dissertação de Mestrado. PPG em Letras, Universidade Federal do Rio Grande do Sul, Porto Alegre.

SANTOS, L.G. (2017). Internacionalização da Língua Portuguesa: o Programa Leitorado Brasileiro. Apresentação de comunicação no VI Encontro Mundial sobre o ensino de Português. Florida International University. Miami.

SCARAMUCCI, M. (2004). Efeito retroativo da avaliação no ensino/aprendizagem de línguas: o estado da arte. Trabalhos em Linguística Aplicada, 43 (2), pp.203-222.

SCHLATTER, M. (2009). O ensino de leitura em lingua estrangeira na escola: uma proposta de letramento. Calidoscópio, v. 7, n. 1, pp. 11-23.

SCHLATTER, M., GARCEZ, P. (2009). Referenciais curriculares do Estado do Rio Grande do Sul: linguagens, códigos e suas tecnologias. Porto Alegre: Secretaria de Estado da Educação, Departamento Pedagógico, v. 1, pp. 127-172.

SCHOFFEN, J. R. (2009). Gêneros do discurso e parâmetros de avaliação de proficiência em português como lingua estrangeira no exame Celpe-Bras. Tese de Doutorado. PPG em Letras, Universidade Federal do Rio Grande do Sul, Porto Alegre.

SCHOFFEN, J. R.; MARTINS, A. F. (2016) Políticas linguísticas e definição de parâmetros para o ensino de português como lingua adicional: perspectivas portuguesa e brasileira. ReVEL, v. 14, n. 26, pp. 271-306. 


\section{ANEXO I - TEXTO}

Recife

Boa Viagem

por Ricardo Freire

@riqfreire Atualizado em 22.Set2017

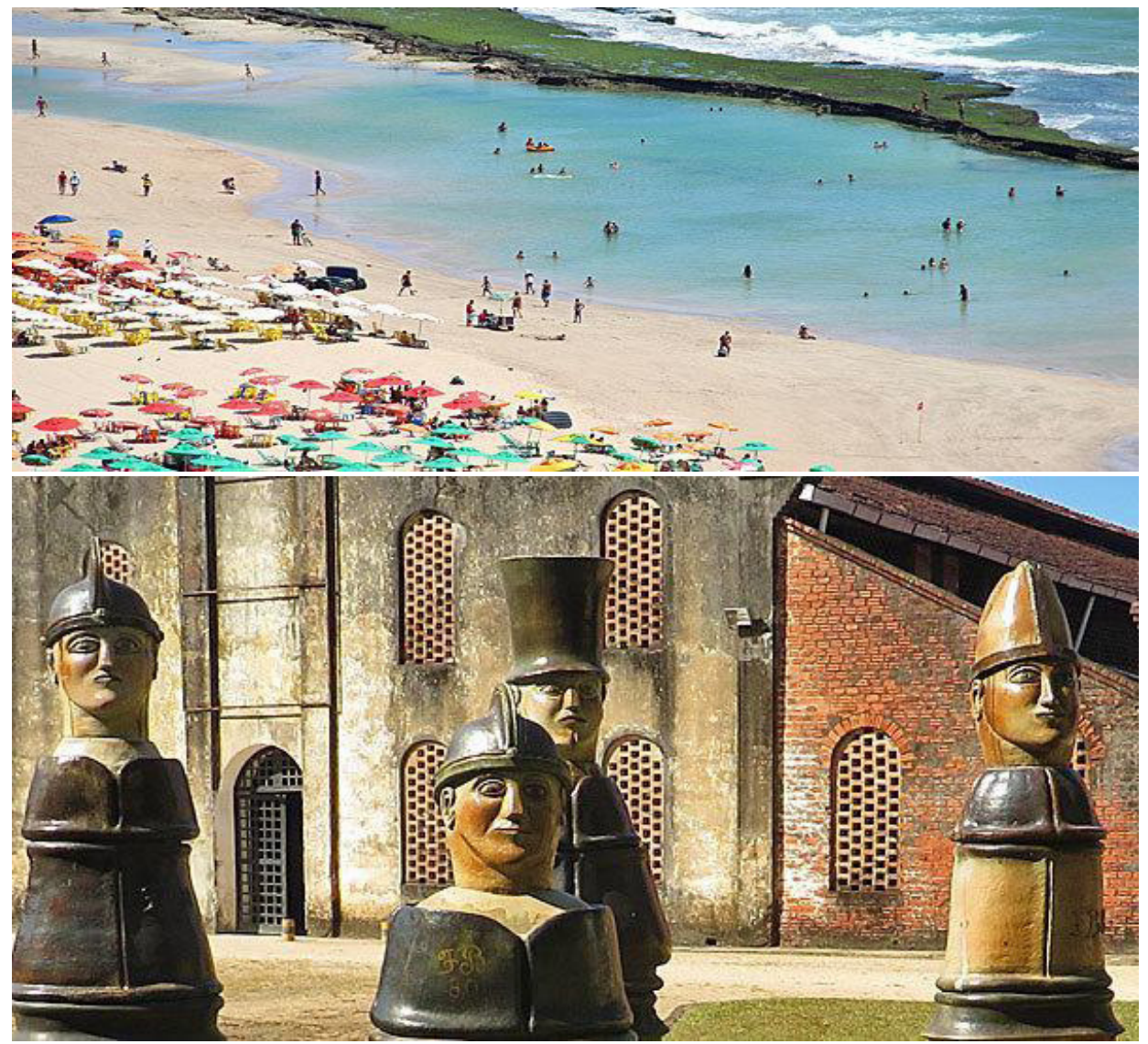

Desde que Porto de Galinhas foi elevado a capital do turismo de massa em Pernambuco, Recife perdeu o seu status de destino de praia.

Tanto melhor: no Recife a praia é um (ótimo) complemento a tudo o mais que a cidade oferece. A saber: dois centros históricos (o Recife Antigo e a vizinha Olinda), vida cultural intensa, gastronomia de qualidade. 
Boa Viagem, o bairro praiano onde está a maioria dos hotéis, é tão auto-suficiente que até o aeroporto fica por lá. Se o trânsito estiver livre e o check-in do seu hotel for eficiente, ao desembarcar você estará a vinte minutos da sua primeira caminhada pelo calçadão.

Mas aproveite para se aventurar longe da praia: na Zona Norte, o bairro de Casa Forte -- e seu núcleo mais antigo, o Poço da Panela -- revela um Recife charmoso e desconhecido dos turistas.

\section{Quando ir}

O tempo firme se estende de setembro a março; outubro, novembro e dezembro são particularmente secos. Maio, junho e julho costumam ser chuvosos.

O Carnaval não acontece só nas datas oficiais: se você aparece nas duas semanas que antecedem a muvuca, já vai se divertir em blocos pré-carnavalescos tanto no Recife Antigo quanto em Olinda.

Caruaru, a 150 km, disputa com Campina Grande (PB) o título de São João mais animado. Mas a viagem ao Alto do Moura para visitar os ateliês dos discípulos de Mestre Vitalino pode ser feita o ano todo.

Recife: quando dá praia?

- Vá! Outubro | Novembro | Dezembro

- Pode ir: Janeiro | Fevereiro | Setembro

- Melhor não ir: Março | $\underline{\text { Agosto }}$

- Não vá: Abril | Maio | Junho | Julho

\section{Como chegar}

O Recife é servido por vôos diretos de São Paulo (Guarulhos), Rio de Janeiro (Galeão), Brasília, Belo Horizonte, Salvador, Fortaleza, Aracaju, Natal, Maceió, Fernando de Noronha, Campina Grande, Petrolina e Juazeiro do Norte.

Do exterior há vôos diretos desde Lisboa, pela TAP, Cidade do Panamá, pela Copa, e Miami, pela American. 
O aeroporto fica a 10 minutos de carro da orla de Boa Viagem. Há dois tipos de táxi no aeroporto: especial, com tabela, e comum, pelo taxímetro; cada um tem seu ponto devidamente marcado na calçada. Vai a Porto de Galinhas e não pretende alugar carro? Veja as opções de transporte aqui.

A propósito, Porto de Galinhas está mais perto: a nova via expressa Rota do Atlântico, pedagiada, começa na ponte de Barra de Jangada (na ponta sul de Jaboatão), atravessa a Reserva do Paiva e o complexo de Suape e vai duplicada até Nossa Senhora do Ó, já na reta final do antigo acesso a Porto, sem precisar passar pelos engarrafamentos da PE 060. A estrada nova também é um excelente atalho para as praias de Cabo de Santo Agostinho.

\section{Onde ficar}

Boa Viagem é a principal zona hoteleira da cidade. O melhor ponto para se hospedar, hoje, é a ponta sul do bairro -- o Pina --, onde estão os hotéis mais novos e com mais restaurantes interessantes para ir a pé. No entanto a melhor barraca de praia, a do Pezão, está a meia hora de caminhada de lá. Veja meu dossiê de hospedagem no Recife aqui.

Olinda está a 15 minutos de táxi do Recife Antigo e meia hora de Boa Viagem (também há ônibus de linha, que levam 90 minutos ou mais entre Olinda e Boa Viagem). A Pousada do Amparo é a mais sofisticada (os apartamentos mais confortáveis estão no anexo); a Pousada dos 4 Cantos tem preços camaradas e o Hotel 7 Colinas, uma piscina irresistível.

A maior novidade no front hoteleiro é o Sheraton Reserva do Paiva, a meio caminho entre o Recife e Porto de Galinhas.

\section{O que fazer}

O Recife Antigo tem duas novas atrações: o Cais do Sertão, que homenageia Luiz Gonzaga, e o Paço do Frevo, um museu do carnaval pernambucano. Visite também a primeira sinagoga das Américas e o observatório da Torre Malakoff. Pegue o barquinho para ir até o Parque de Esculturas de Francisco Brennand, plantado no recife que deu nome à cidade. Almoce na Casa de Banhos (que também está localizada no recife) ou no Bistrô \& Boteco, anexo ao Cais do Sertão. Um desfecho para um dia no centro histórico pode ser o passeio de catamarã pelo Capibaribe, que sai dali na praça do Marco Zero. 
Olinda é melhor visitada com sol baixo; chegue para almoçar tipo às $13 \mathrm{~h} 30$ (no Beijupirá, na Oficina do Sabor ou no Patuá) e faça a digestão no sobe-desce-ladeira.

Entre 3a. e 6a., vá ao bairro da Várzea visitar o museu-ateliê de Francisco Brennand (abre de 2a. a 6a.) e o a coleção de arte e armas do Instituto Ricardo Brennand (abre de 3a. a domingo). O tour pode continuar pela Fundação Gilberto Freyre e pelo bairro do Poço da Panela. Eu conto como fazer neste post.

A ilha de Itamaracá, $70 \mathrm{~km}$ ao norte, rende um passeio de um dia inteiro, com visita ao Forte Orange, praia na ilhota da Coroa do Avião e uma passada no Projeto PeixeBoi. No caminho faça um desvio para ver o centro histórico de Igarassu.

Se você quer fazer um bate-volta a Porto de Galinhas, consulte a tábua das marés; é na maré baixa que aparecem as piscinas naturais e a praia fica boa para entrar n'água.

Fonte: https://www.viajenaviagem.com/destino/recife

Recebido: 4/06/2019

Aceito: 26/09/2019

Publicado: 2/10/2019 